\title{
Systematische Verbesserung des Lackierprozesses
}

\author{
Durch eine ganzheitliche Betrachtung der Filtertechnik können Anlagenbetreiber das \\ Lackierergebnis dauerhaft verbessern und Lackdefekte vermeiden. Möglich wird dies \\ durch den Einsatz frei kombinierbarer Servicemodule.
}

Das neu vorgestellte FiltermanagementSystem von Freudenberg besteht aus verschiedenen Servicepaketen, die beim Lackieren für reine Luft und makellos glänzende Ergebnisse sorgen. In der Prozessanalyse und -optimierung bietet Freudenberg seine Expertise nun außerhalb fester, dauerhafter Serviceverträge an unabhängig davon, ob ein Anwender in einer Lackieranlage Viledon-Filter einsetzt oder nicht.

Freudenberg analysiert in diesem Rahmen sämtliche Faktoren, die den Lackierprozess beeinflussen. Dabei beraten die Ingenieure und Servicetechniker unabhängig von den verwendeten Filter-Produkten und unabhängig von den Interessen eines Lackieranlagenherstellers.

Sieben Module stehen bei dem Filtermanagement-System Viledon FilterCair zur Auswahl. Im Basis-Modul decken die Servicetechniker von Freudenberg Filtration Technologies vor allem qualitätsmindernde Verschmutzungen im Lackierprozess systematisch auf, messen unter anderem
Staub-, Partikelgehalt, Sinkgeschwindigkeiten und die relative Luftfeuchte. Darauf aufbauend beinhaltet das Modul „Basic + Dirt in Paint“ Lackschadensanalysen - dies beinhaltet Analysen vor Ort und im Labor, zum Beispiel mittels Elektronen- und Infrarotmikroskopie.

Lackschäden sind häufig auf Fasern und Flusen zurückzuführen, die aus den im Prozess verwendeten, textilen Materialien wie Roboter-Schutzstrümpfe, Lackieroveralls, Schleif-Pads oder beispielsweise Reinigungstüchern stammen können. Für Analysen solcher Betriebsmittel gibt es daher ein eigenes Servicemodul. Weitere Leistungspakete widmen sich ganz gezielt den Strömungsverhältnissen in der Lackieranlage sowie den Themen Druckluft und Lacktrocknung. Einzelne Module sind nach ihrem spezifischen Bedarf individuell miteinander kombinierbar, für Großserien-Lackieranlagen genauso wie für Reparaturkabinen.

Mit der ganzheitlichen Betrachtung werden Lackdefekte vermieden und so lang- fristig das Lackierergebnis verbessert. Durch effizientere Prozesse - etwa durch entfallende Prozessschritte wie Nachpolieren oder Nachlackieren - entstehen zusätzlich Zeit- und Kosteneinsparungen. Ergänzt wird dies durch einen umfassenden, nutzerfreundlich aufbereiteten, interaktiven Report. Dieser ist auditrelevant, zeigt für die untersuchten Lackierprobleme individuelle Optimierungspotenziale und Handlungsempfehlungen auf und kann bei zukünftigen Maßnahmen weitergeführt werden. //

\section{Kontakt}

\section{Freudenberg Filtration}

Technologies SE \& Co. KG

Weinheim

Tel. 06201800

info@freudenberg-filter.com

www.freudenberg-filter.de

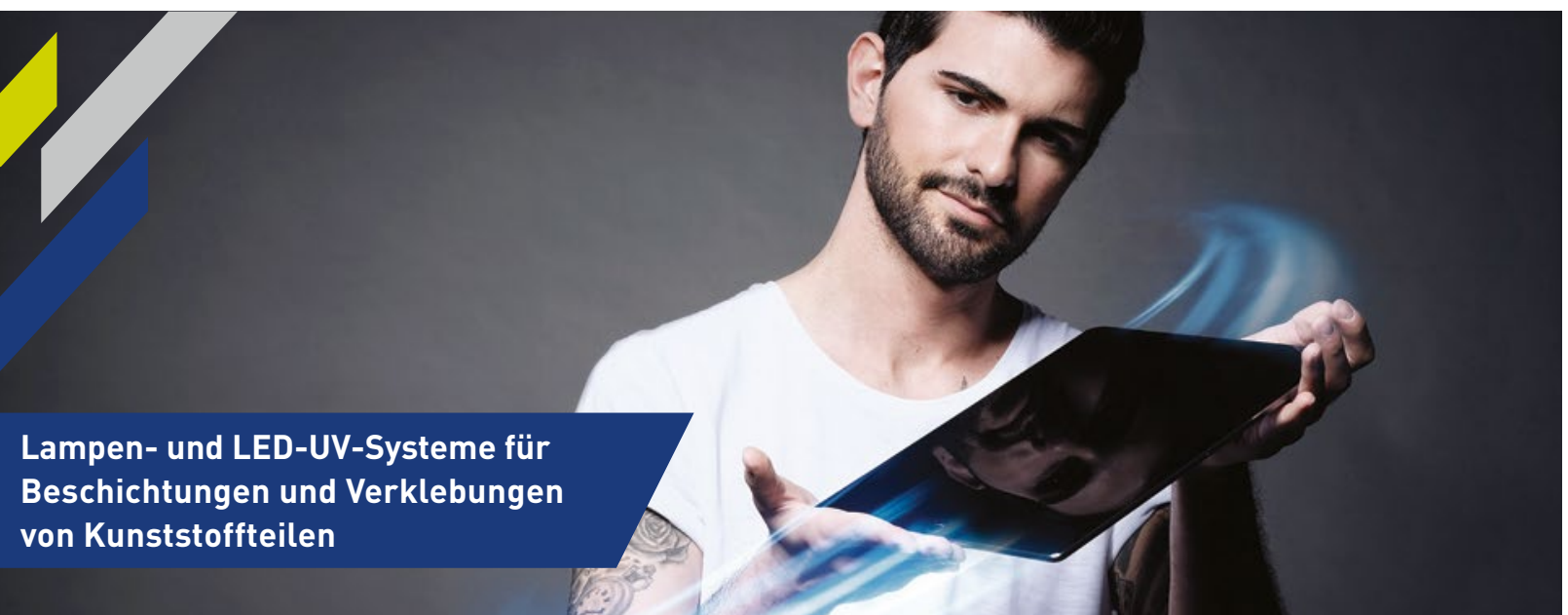

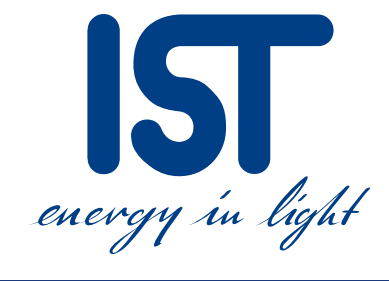

IST METZ GmbH Lauterstraße 14-18 72622 Nürtingen Tel. +49 7022 60 02-0 www.ist-uv.com 